University of Nebraska - Lincoln

DigitalCommons@University of Nebraska - Lincoln

Faculty Publications from the Department of Electrical \& Computer Engineering, Department Electrical and Computer Engineering

2000

\title{
A Comparative Study of UWB FOPEN Radar Imaging Using Step- Frequency and Random Noise Waveforms
}

Xiaojian Xu

University of Nebraska-Lincoln

Ram M. Narayanan

University of Nebraska-Lincoln

Follow this and additional works at: https://digitalcommons.unl.edu/electricalengineeringfacpub

Part of the Electrical and Computer Engineering Commons

$\mathrm{Xu}$, Xiaojian and Narayanan, Ram M., "A Comparative Study of UWB FOPEN Radar Imaging Using StepFrequency and Random Noise Waveforms" (2000). Faculty Publications from the Department of Electrical and Computer Engineering. 150.

https://digitalcommons.unl.edu/electricalengineeringfacpub/150

This Article is brought to you for free and open access by the Electrical \& Computer Engineering, Department of at DigitalCommons@University of Nebraska - Lincoln. It has been accepted for inclusion in Faculty Publications from the Department of Electrical and Computer Engineering by an authorized administrator of DigitalCommons@University of Nebraska - Lincoln. 


\title{
A Comparative Study of UWB FOPEN Radar Imaging Using Step-Frequency and Random Noise Waveforms
}

\author{
Xiaojian $\mathrm{Xu}^{\star}$ and Ram M. Narayanan \\ Department of Electrical Engineering and Center for Electro-Optics \\ University of Nebraska, Lincoln, NE 68588-0511 \\ Tel: 402-472-5141, Fax: 402-472-4732, Email: rnarayanan@unl.edu
}

\section{Introduction}

The detection and identification of targets that are obscured by foliage have been topics of great interest. Several experimental developments of such ultrawideband (UWB) radars have been published. By operating in the VHF and UHF frequency bands and using either LFM or step-frequency waveforms, these radars have demonstrated promising images of terrain and man-made objects obscured by dense foliage [1].

The University of Nebraska has developed a new technique that permits coherent processing of backscatter data acquired by a radar that transmits UWB random noise signals. This technique has been used in various applications, such as ground penetration detection of buried objects, Doppler estimation and interferometry, and SAR and ISAR imaging [2]. In this paper, by a comparative study of the radar images using stepfrequency and random noise waveforms, we demonstrate the ability of the UHF band UWB random noise radar for foliage penetration (FOPEN) surveillance applications.

\section{Brief Description of the Radar Systems}

Simplified system diagrams of the two kinds of radar systems are shown in Figure 1. The step-frequency radar transmits $\mathrm{CW}$ signal and measures the amplitude and phase of the backscattered signals. The transmit waveform is stepped through a set of discrete frequencies over the operating bandwidth. The noise radar transmits a truly random noise signal within the desired frequency range and processes the target echoes by employing a heterodyne correlation receiver. Thus, both systems can obtain the I and $\mathrm{Q}$ signals of the scattering echoes.

\section{Foliage Transmission Modeling}

Based on the experimental observations by researchers in Air Force Research Laboratory, MIT Lincoln laboratory, and ERIM [3-5], a statistical-physical model for foliage transmission has been developed. The frequency, depression angle, polarization and flight path dependent attenuation and amplitude and phase fluctuation can be expressed as

$$
A(f, \gamma, \theta)=A_{m}\left[1+\delta_{f}(f) \delta_{p}(\theta)\right] e^{j \delta_{\phi}(f, \theta)}
$$

where $A_{m}$ is the mean attenuation, $\delta_{f}(f)$ and $\delta_{p}(\theta)$ represent the frequency and path dependent amplitude fluctuations, respectively, and $\delta_{\phi}(f, \theta)$ represents the phase fluctuation.

Following M.E. Davis [1], the mean attenuation of the foliage can be modeled as

$$
A_{m}(d B)=\beta f^{\alpha}\left(\sin 45^{\circ} / \sin \gamma\right)
$$

where $f$ is the frequency in $\mathrm{MHz}, \gamma$ is the depression angle, and $\alpha$ and $\beta$ are two constants. For $\mathrm{HH}$ polarization, $\alpha=0.79, \beta=0.05$; and for VV polarization, $\alpha=0.5$, $\beta=0.45$. 
The frequency dependent amplitude fluctuation, $\delta_{f}(f)$, is modeled as a random process having Gamma probability density,

$$
p(x, a, b)=\frac{1}{b^{a} \Gamma(a)} x^{a-1} e^{-x / b}
$$

where constants $a$ and $b$ are determined by the mean and variance of the amplitude fluctuation.

The flight path dependent amplitude fluctuation $\delta_{p}(\theta)$ is modeled as

$$
\delta_{p}(\theta)=e^{\eta(\theta)}
$$

where $\eta(\theta)$ is a Wiener process. as $[6]$

The phase fluctuation is related to the amplitude fluctuations and can be expressed

$$
\delta_{\phi}(f, \theta)=\tan ^{-1}\left(\frac{\delta_{m} \sin \phi}{1+\delta_{m} \cos \phi}\right)
$$

where $\delta_{m}=A_{m} \delta_{f} \delta_{p}$, and $\phi$ has an uniform density over $[0,2 \pi]$.

\section{Simulation Results}

\subsection{Validation of the foliage transmission model}

A number of simulation experiments were conducted to validate the foliage transmission model. Figure 2 shows the cumulative probability distribution of the two-way attenuation fluctuation generated by the model, with comparisons to the foliage penetration experiment data in [3]. The model results show good consistency with the experimental data.

\subsection{Comparison of the PSFs}

The foliage obscured point spread functions (PSF) in down range for the step-frequency and random noise radars are shown in Figure 3. It is seen that the PSFs of the two systems, when affected by the foliage, behave in the similar ways: the energy of mainlobes is attenuated, and the levels of the sidelobes are increased. The foliage obscured PSFs in cross range have the similar behavior.

\subsection{Comparison of the 2-D images}

The signature data of a scaled target model were acquired in an anechoic chamber using a step-frequency radar. The physical size of the model is about $0.85 \mathrm{~m} \times 0.65$ $\mathrm{m}$, measured at central frequency $10 \mathrm{GHz}$ with a bandwidth of $6 \mathrm{GHz}$. When scaled to UHF band by a scale factor of 26.67 , the equivalent central frequency is $375 \mathrm{MHz}$ with a bandwidth of $225 \mathrm{MHz}$, and the full size of the target is $22.7 \mathrm{~m} \times 17 \mathrm{~m}$. The two-dimensional (2-D) images of the above target for the step-frequency and the noise radar systems are illustrated in Figure 4 and 5, respectively. From these figures, it can be seen that, whether the target is or not obscured by foliage; the 2-D images of the two radar systems for each case are very similar to each other. This indicates that the random noise waveform has comparable performance to the step-frequency system.

\section{Conclusions}

We have compared the behavior of a step-frequency radar and a random noise radar for FOPEN imaging applications. It can be seen that the two radar systems are nearly 


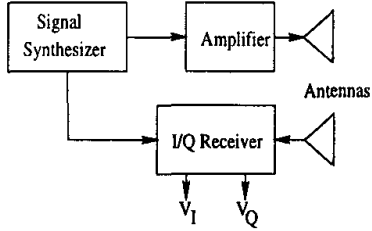

(a). Step-frequency radar

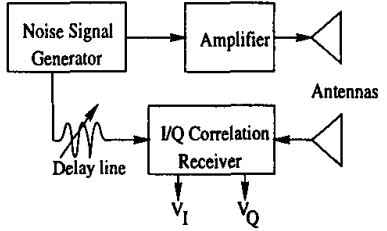

(b). Coherent random noise radar

Figure 1: Simplified diagrams of the two radar systems.

identical in the quality of images either without or with obscuring foliage. Our results demonstrate the ability of the UWB random noise radar to be used as a FOPEN SAR, with relative immunity from interference and detection.

\section{Acknowledgments}

This work was supported by Air Force Office of Scientific Research (AFOSR) under contract F 49620-99-1-0209. Thanks are due to Dr. Arje Nachman of AFOSR for helpful comments and support of the research.

\section{References}

[1] M.E. Davis, P.G. Tomlinson, and R.P. Malony, "Technical challenges in ultrawideband radar development for target detection and terrain mapping," Proc. IEEE Radar Conf., Boston (MA), April 1999, pp.1-7.

[2] R.M. Narayanan, Y. Xu, P.D. Hoffmeyer, and J.O. Curtis, "Design, performance, and applications of a coherent ultra-wideband random noise radar," Opt. Eng., Vol.37, No.6, June 1998, pp.1855-1869.

[3] J.G. Fleischman, S. Ayasli, E.M. Adams, and D.R. Gosselin, "Foliage penetration experiment, Part I: Foliage attenuation and backscatter analysis of SAR imagery," IEEE Trans. on Aerospace and Electronic Systems, Vol.32, No.1, Jan. 1996, pp.134-144.

[4] M.F. Toups, Ayasli, and J.G. Fleischman, "Foliage penetration experiment, Part II: Foliage-induced synthetic pattern distortion," IEEE Trans. on Aerospace and Electronic Systems, Vol.32, No.1, Jan. 1996, pp.145-155.

[5] D.R.Sheen, N.P. Malinas, D.W. Kletzli,Jr., T.B. Lewis, and J.F. Roman, "Foliage transmission measurement using a ground-based Ultrawide band (300-1300 MHz) SAR system," IEEE Trans. on Geoscience and Remote Sensing, Vol.32, No.1, Jan. 1994, pp.118-130.

[6] G.C. Hsu, J.A. Kong, M.F. Toups, J.G. Fleischman, S. Ayasli, and R.T. Shin, "Electromagnetic modeling of foliage obscured point source response," Proc. SPIE Conf. on Underground and Obscured Object Imaging and Detection, Vol.1942, Oriando (FL), April 1993, pp.76-87. 

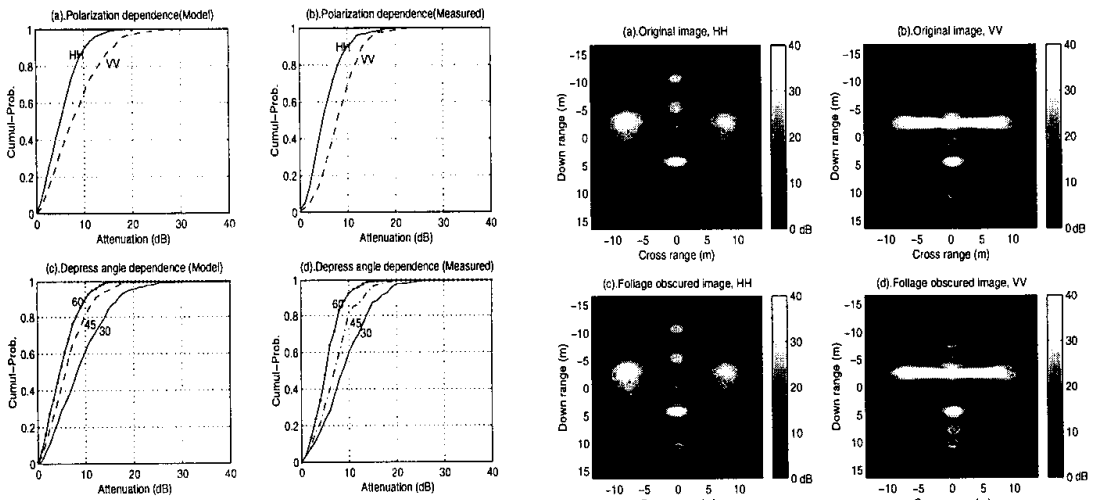

Figure 2: Comparison of the cumulative probability distributions.
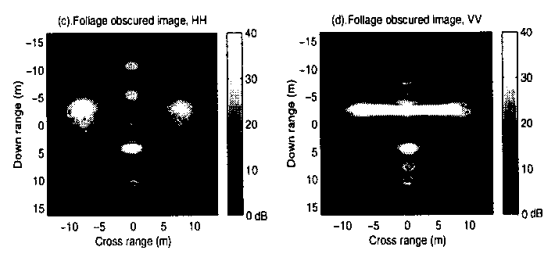

Figure 4: 2-D images of step-frequency SAR.
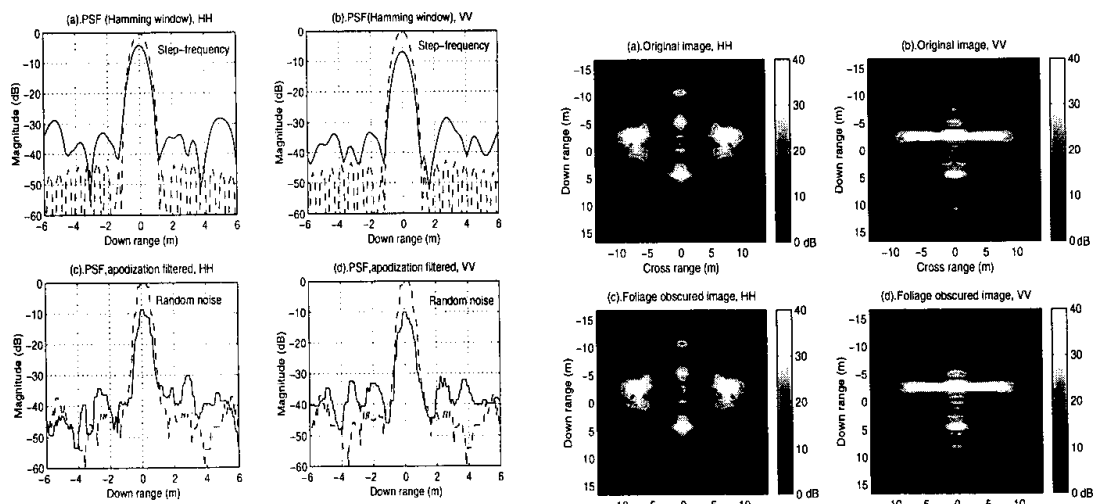

Figure 3: Down range PSFs of the two radar systems. The dashed lines are without foliage, the solid lines are with foliage.
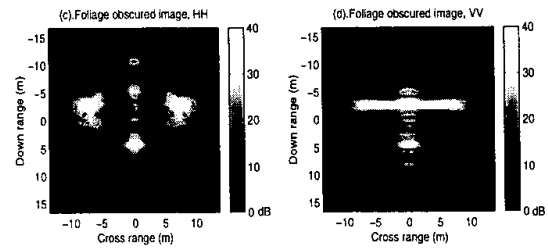

Figure 5: 2-D images of random noise SAR. 